\title{
ONLINE STUDYING INSTRUCTIONAL MEASURES AT THE INTERNATIONAL RELATIONS DEPARTMENT OF THE NATIONAL UNIVERSITY OF OSTROH ACADEMY
}

\author{
MARIIA AVHUSTIUK, PHD \\ International Relations Department, National University of Ostroh Academy \\ Seminarska Str. 2, Ostroh, Rivne Region, 35800 \\ E-mail: mariia.avgustiuk@oa.edu.ua \\ ORCID: 0000-0001-8041-5078 \\ TYMEICHUK IRYNA, PHD \\ Department of Psychology and Pedagogy, National University of Ostroh Academy \\ Seminarska Street 2, Ostroh, Rivne Region, 35800 \\ E-mail: iryna.tymeychuk@oa.edu.ua \\ ORCID: 0000-0003-3640-9847 \\ NATALIA KONOPKA, PHD \\ Department of Psychology and Pedagogy, National University of Ostroh Academy \\ Seminarska street 2, Ostroh, Rivne Region, 35800 \\ E-mail: natalia.konopka@oa.edu.ua \\ ORCID: 0000-0002-1245-3459 \\ OKSANA SAKHIUK, PHD \\ Department of Psychology and Pedagogy, National University of Ostroh Academy \\ Seminarska street 2, Ostroh, Rivne Region, 35800 \\ E-mail: oksana.sakhniuk@oa.edu.ua \\ ORCID: 0000-0001-9468-8181 \\ EDUARD BALASHOV, PHD \\ Department of Psychology and Pedagogy, National University of Ostroh Academy \\ Seminarska street 2, Ostroh, Rivne Region, 35800 \\ E-mail: eduard.balashov@oa.edu.ua \\ ORCID: 0000-0002-6486-0494 \\ SCOPUS ID: 56705096900 \\ Web of Science ResearcherID: T-3405-2019
}

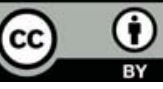




\section{ABSTRACT}

Aim. The paper's aim is to present some current specific online studying instructional measures at the International Relations Department of the National University of Ostroh Academy in Ukraine.

Methods. The study is devoted to the observation of some theoretical and methodological aspects of the peculiarities of online studying measures at the International Relations Department. The theoretical and comparative methods of analysing the peculiarities of online studying have been taken into account. In order to summarise the current online studying experiences at the International Relations Department, some specific instructional measures for both students and teachers are presented, for example: how to handle the lack of interaction, master self-learning, promote self-regulation strategies and become more strategic thinkers.. The necessity of studying the above-mentioned aspects has been caused by their impact on students' learning activity, especially in the times of COVID-19 pandemic.

Results and conclusions. The focal point of this research is to provide an insight into the background of online studying peculiarities through the prism of Ukrainian teachers and students. The analysis is focused on online studying of foreign languages, as well as the possible online teaching methods of professional disciplines (History of International Relations; Foreign Policy of the Countries of Asia, Africa, and Latin America; International Conflicts; Current Problems of International Relations in the Middle East) at the International Relations Department. What is more, the authors outline how to help students deal with the lack of interaction, master self-learning, promote self-regulation strategies and become more strategic thinkers. The authors also highlight possible challenges for the faculty and suggest ways to overcome those difficulties. Moreover, some major prerequisites of students' self-regulatory online learning are described.

Contribution. The results of the study are instrumental in mastering the peculiarities of online studying through the prism of learning at the International Relations Department of the National University of Ostroh Academy (Ukraine). The findings of this study may be considered important and contribute to future research.

Key words: online studying, self-learning, performance, self-regulated learning

\section{INTRODUCTION}

$\mathrm{O}$ line studying may be considereda challenging and controversial notion in enhancing and improving student learning outcomes. Traditionally, the effectiveness of learning in the online environment has been compared to traditional face-to-face studying format and the factors which may influence the effectiveness of online courses. Numerous studies have been published to compare traditional and online programs in different educational institutions (Summers et al., 2005; Pai, 2013; Brown \& Park, 2016). Thus, by traditional learning, we understand the educational process in a classroom setting, moderated by the instructor. On the contrary the online learning takes place on the Internet and students are not required to be physically present on campus.

The study of Nguyen (2015) focuses on examining the evidence of learning effectiveness in the online environment. The author suggests that such studying is generally at least as effective as the traditional one. A noteworthy finding is that studying in the online environment has the potential to create educa- 
tional opportunities for students who may have faced the so-called unsurpassable barriers prior to the expansion of online educational programs (Gilbert, 2015).

Since the outbreak of coronavirus pandemic, most faculty members have faced some major challenges, such as lack of online teaching experience or no efficient support from educational technology teams. At the same time, selfisolated students also frequently experience difficulties, such as the lack of self-discipline, appropriate study materials, or proper learning environment (Bao, 2020). Consequently, successful online studying may consist of five high-impact principles. These are: 1 . considerable relevance between online instructional design and student learning; 2. efficiency of online instructional information; 3 . sufficient assistance for students provided by faculty staff; 4 . high-quality participation to expand the whole process of student online learning; 5. contingency strategy to cope with unforeseen incidents of online educational platforms (Bao, 2020).

Accordingly, serious problems in studying in the online environment exist. The discussions on how the faculty should effectively implement instructional strategies to prevent university students from negative learning attitudes and promotes online learning efficiency are still ongoing.

Learning in the online environment is conducive to students who prefer self-regulated learning (You \& Kang, 2014). The authors highlight that self-regulated learners tend to use various cognitive and metacognitive strategies with an aim to achieve their learning goals (You \& Kang, 2014). According to Jansen (2017), students in the online environment should regulate their learning to a greater extent in comparison to students in traditional, face-to-face education, or non-formal education (Balashov et al., 2016).

The online context requireslearners to use their minds more, instead of passively absorbing the knowledge from a teacher. Learners must monitor the learning process as they absorb the information delivered over the Internet. Thus, according to Carrier (1984), the hypermedia environment presents the additional problem of staying concentrated on academic objectives and resources management. As a result, successful learners should form a judgment when interacting with infinite volumes of data accessible while studying online.

Moreover, according to Zimmerman (1990), learning in the online environment (as well as the traditional one) as a challenging construct of university education is not something that happens to students, but undoubtedly something that happens by students. As self-regulated learning focuses primarily on one's ability to think metacognitively, motivationally, and behaviorally (Zimmerman, 1990), learning in the online environment is highly dependent on an individual's ability to direct and manage not only the learning process in general (Boekaerts, 1999) but also time and resources (Anderton, 2006). In such circumstances, learning how to learn has become an essential educational issue (Williamson, 2015).

Good self-regulators are characterised by developing such skills as exhibiting effective learning strategies, effort, and persistence. Such learners are 
more confident at adapting learning strategies reflectively and more flexible at task analysis, strategies use, and monitoring. Consequently, three main components of self-regulated learning should be highlighted: cognition (the skills and habits necessary for encoding, memorising, and recalling information, as well as thinking critically), metacognition (the skills which give students an opportunity to understand and monitor their cognitive processes while studying online), and motivation (the beliefs and attitudes aimed at affecting the use and development of both the cognitive and metacognitive skills). Thus, in order to be a successful learner in the online environment, one needs to be able to rapidly transfer the awareness and strategies attained in one situation to new circumstances, adjusting and extending these strategies on the way. Various concepts of successful cognitive processing have been acknowledged, including such metacognitive skills as orienting, planning, executing, monitoring, evaluating, and correcting. These are the monitoring and self-regulatory skills which give students the possibility to be aware of not only what is essential (declarative knowledge) but also how (procedural knowledge), when, where, and why (conditional knowledge) to apply the proper awareness and actions. If the online technology is unknown to the learners, one should gain familiarity therewith in addition to the course content (Anderton, 2006).

Traditional face-to-face studying has long been the only appropriate mode of learning for the faculty at the International Relations Department. However, the COVID-19 pandemic outbreak has dramatically affected the educational system worldwide, leading to a sharp shift resulting in the online studying. Therefore, quick adaptation to the new conditions was necessary which launched numerous challenges for educators, as they absorb the information delivered any of which were faced previously. They may involve an effective organization of the studying process, time management skills, Internet connectivity, lack of interaction, etc. While studying online, it is challenging for teachers to keep students effectively engaged without a physical presence and face-to-face interaction. A possible solution to keep students engaged while studying online is to develop their self-learning and self-regulation techniques. Consequently, we aim at highlighting some of the challenges a faculty may face during the process of online learning. We try to suggestpossible ways in which teachers can overcome their problems while helping students master self-learning, promote self-regulation strategies, become more strategic thinkers, and deal with lack of interaction among them.

\section{METHODOLOGY}

This study focuses on the case of the International Relations Department of the National University of Ostroh Academy (Ukraine) students' learning and performance in the online environment. In particular, based on observations of online teaching at the University, the paper aims to present some specific instructional measures for both students and teachers on how to handle the 
lack of interaction, master self-learning, promote self-regulation strategies and become more strategic thinkers through the analysis of some of the current online studying experiences. In order to achieve this aim, we sought to analyse online studying of foreign languages, as well as the possible methods of online teaching of professional disciplines (History of International Relations; Foreign Policy of the Countries of Asia, Africa, and Latin America; International Conflicts Current Problems of International Relations in the Middle East). We also provide some major prerequisites of students' self-regulatory online learning suitable for the International Relations Department students.

\section{RESULTS AND DISCUSSION}

Peculiarities of online studying of foreign languages and professional disciplines at the International Relations Department

While studying foreign languages and professional disciplines at the International Relations Department, students handle tasks that aim to enrich their knowledge of the major and improve foreign language skills. The successful studying process involves careful planning, design, development, evaluation, and implementation so that it fosters learning and is meaningful for students. To reach this goal, teachers have to modify some of the speaking, listening, reading, and writing tasks during online studying.

Firstly, the activities which let students practice social and practical conversations through work in pairs and groups via Google Meet, Skype, Zoom, Cisco Webex, etc., can be organised and transformed to assist students to cope with a shortage of interpersonal face-to-face communication. For example, a typical task for pair work sounds as follows: "Ask students to memorise words and their definitions/ synonyms/antonyms and then work in pairs and test each other" and can sometimes be transformed into a teacher-group mode. A teacher randomly asks students to give a synonym/ antonym to a word and discuss its definition in a group so that students interact with each other more. Moreover, a teacher can think of increasing the amount of time for discussions in small groups of three to five students since it can help them deal with isolation and feel more integrated while studying online.

Some brainstorming lead-in tasks (for example: "Brainstorm the words to the following topic...") have to be transformed because students cannot talk simultaneously and be heard due to the differences in Internet connection speed. Thus, the recommended way to transform the task is to ask students to type their words in chat. Some comments on the misspellings can be made if necessary, and a short discussion on associations can be held.

It is also a sensible proposition to change a teacher-group mode to a student-led class from time to time. Students can have various responsibilities and home tasks for the class, e.g., be in charge of discussions and hold talks. A student-led discussion teaches an executor to be more responsible and creative while preparing for a class and thinking about the possible questions to 
be asked during the discussion. By choosing a student responsible for vocabulary presentation before video and audio activities, a teacher also encourages the development of self-regulation techniques. Furthermore, a teacher can also help the rest of the group feel more integrated into the process by assigning them tasks to propose variants of translation of the presented lexical units and come up with their own examples. Therefore, such modified activities can demonstrate how students apply conditional awareness of a language and teach them how to develop self-learning and self-regulation techniques and think more strategically.

Secondly, some changes can be made in listening and watching activities. Pre-listening and pre-watching discussions may become longer to increase the amount of speaking interaction. Moreover, a teacher has to raise students' awareness and underline that such tasks (e.g. listening to a text and filling in the gaps in sentences, marking the statements true or false, choosing a correct variant, and then discussing and comparing answers) teach them to how to self-evaluate and monitor the development of their skills individually.

Some tasks of the listening activity, oriented on improving pronunciation and intonation by repeating things in a choir, can be transformed because of an impossibility for students to chant the words together due to different speeds in Internet connection. Therefore, the possible way to substitute the task is to teach them to work on pronunciation individually. For instance, a teacher may ask participants to record themselves reading the sentences as their home task, evaluate their work, and send the best variant to a teacher. In such a way, a teacher can analyse each student's progress and give advice if needed while students learn how to set a goal (make the best recording), self-record, selfevaluate, and self-judge the result.

Singing activity, which is widely used as an activity aimed at improving intonation and linking skills, can be hard to conduct due to Internet connection fluctuations. Typically, students are asked to fill in the gaps in a song, analyse linking, and then sing the song in a choir, taking into account pronunciation. During online studying, a teacher can substitute a song with a poem or a tongue twister, ask students to guess what the missing words in gaps are, provide definitions to these words, deal with linking, and listen to students reading it as a warm-up exercise at the beginning of the class. It takes several minutes, but warms up the participants' articulatory system and serves as an energising exercise. Finally, a teacher can also raise students' awareness that further individual work will definitely result in a good pronunciation.

Thirdly, reading activity may be aimed at developing self-regulation strategies. Resource books include texts with various reading tasks, e. g., choose A, B, C, D; mark the statements true or false; match the heading to the paragraphs; put paragraphs in the correct order; etc. It is vital to teach students how to accomplish these tasks since they are usually included in IELTS and TOEFL exams (these tests are required by most Master and PhD programmes). However, before dealing with such exercises, a teacher should underline the importance of self-control and self-observation because some students may be lured 
to cheat. Firstly, being at home and working at the computer, students can use dictionaries and free automatic translation services as Google Translator to translate the texts which are supposed to be read without dictionary assistance. Secondly, they can easily share their answers with other group participants using their phones or social networks to which they have access when working online. Therefore, for this kind of reading task, it is crucial to teach students to develop reading skills and master self-regulation techniques; however, it is not preferable as a means of the final evaluation of student knowledge acquisition.

Reading and writing activities are actively used to shape students' strategic thinking. For this reason, the faculty tends to use articles on international relations topics in order to increase professional vocabulary and widen students' horizons in the sphere of their expertise. Having read an article, a student presents a critical review or writes a summary of it. Writing essays and articles, which are primary tasks checking students' ability to express their thoughts and views in a foreign language, also aims to develop creative and critical thinking.

Furthermore, writing as the fourth primary activity facilitates self-regulation. A typical form of a written task is doing exercises. Students may prefer typing grammar exercises to writing them in hand; nevertheless, a teacher should understand that students can copy somebody's text into their files. As a result, it is advisable to focus students' attention on their aims and task strategies, and then ask them to write their answers in hand in the copybooks, sending photos of the accomplished tasks afterwards. The necessity of pictures' good quality should be underlined.

Moreover, if students are to make a new vocabulary list, a written-in-hand variant is advisable because otherwise, they may copy definitions from online dictionaries and paste them into a file. Although some people might consider writing in hand to be outdated, one should not forget that students learn how the word is written when doing so. Unfortunately, when asked to type something, students tend to use an automatic spelling checker, and, as a result, they happen to make mistakes when writing in hand in the future. Therefore, a teacher's task is to make it clear why this kind of approach is essential.

Since students at the International Relations Department study a lot of specialised vocabulary, their knowledge should be monitored by teachers and by students themselves throughout the whole period of online studying with the help of oral dictations. Moreover, short lexical dictations or timed complicated tests can be created with the help of the online educational platform IC Moodle. Complex tests may consist of several parts to check different skills: listening, grammar, vocabulary, writing, etc. They can be generated for practice: allow students multiple access and provide answers for self-check. However, they may also be created to assess student learning. In this case, it is recommended to limit the tests to only one attempt and to set them up to be completed within a specified time limit. To alert a student to the remaining time, a countdown timer is shown. Furthermore, short lexical warm-ups are recommended to control vocabulary enhancement. If a teacher wants students to interact more, he 
or she may provide definitions or translation of the words into the native language and ask for the words or vice versa.

One more activity that needs adjustment during online studying is the explanation of grammar rules. It is clear that not all students perceive the information in the same way. While studying online, the learners' non-verbal reactions are often hard to discern, making it difficult for a teacher to effectively assess whether a student understands the new grammar or is completely lost. The possible solution may be creating the IC Moodle digital folder containing all the materials on the topic (PowerPoint presentations with vivid examples illustrating the necessary grammar material, handouts, videos, exercises, links to different sites, etc.). A teacher can present the new grammar topics to the class during the online session and then refer students to the digital folder for further and more effective processing of the material.

However, due to the switch to the online learning environment, not only the studying process needs adjustment. The psychological aspects of online education are to be considered as well. First and foremost, to deal with the lack of interpersonal face-to-face communication felt by students, it is advisable for a teacher to work with the camera on, using his or her body language and facial expression as often as possible. Video chats, discussion boards, and chat rooms may be used to help cope with the negative effects of the absence of live communication. The promotion of increased interaction between online students is also required.

Giving instructions is another aspect that needs careful observation. Having inadequate or ambiguous online instructions can be harmful to a student's selfmotivation and self-learning. Therefore, a teacher should be precise and give exact instructions to students so that they do not feel lost or disappointed. If any questions still arise, fast and trouble-free communication with a teacher (via e-mail, chat, etc.) will be advantageous.

Studying online, some students might also feel the lack of immediate faceto-face feedback which makes the process of learning more comfortable and better. Personalised feedback improves students' self-esteem and motivation; the absence of it makes them feel perplexed. The possible solution may be to give them some self-evaluation questionnaires and schedule some extra video chats with a teacher (one hour per week, for example), which function similarly to consultations during on-campus training. In online studying conditions, all kinds of class and home tasks, if appropriately modified, can help students deal with lack of interaction, master self-learning, promote self-regulation strategies, and become strategic thinkers.

While studying online, the usage of various platforms can help students with self-learning and self-regulation. The one that is especially popular among the educators at the International Relations Department is IC Moodle. Not only is this open-source platform easy to use, but it also provides vast opportunities for teachers and students. IC Moodle may be used to create and manage virtual classrooms, in which students can interact with a teacher and each other, access different video/audio materials, documents, quizzes, and 
tests. The latter provide the opportunity to monitor students' progress through the whole period of studying. It is also advisable to include various types of questions into tests, such as multiple-choice, fill in the blank, essay, etc., which will make the assessment more accurate. Many of these are set up to be graded automatically, which saves a teacher's time significantly. Furthermore, IC Moodle can be used to carry out the self-evaluation and final assessment of knowledge acquisition. The system allows conducting tests and exams, including tasks to define terms and explain concepts as well as other written tasks.

Regarding studying professional disciplines online (i.e., History of International Relations; Foreign Policy of the Countries of Asia, Africa, and Latin America; International Conflicts; Current Problems of International Relations in the Middle East), it is crucial to encourage students to work with primary sources for analytical processing of the material. During the online practical classes held in groups, a number of individual research tasks in the form of analytical notes, scientific essays, and presentations increases. IC Moodle may be used to house methodological, practical, as well as informative materials and resources to conduct different tasks and prepare both midterm and final tests. Such activities aim to help students self-study, regulate work, evaluate personal achievements, and develop critical thinking.

Following a teacher's instructions and complying with specific requirements, a student learns to responsibly structure and choose the content of research material; to present it concisely, with the maximum informativeness of the text; to avoid information accumulation; to carefully structure the information; to highlight essential information (e.g. conclusions, definitions, rules, etc.). The self-instruction method gives a student the opportunity to work at a personal pace and thus to evaluate personal results.

A teacher can recommend presenting the material to a small focus group, audience or friends and asking about their opinion regarding the presentation's content and style. Students learn to perceive that absolute mastery of this topic, maximum engagement of the audience, and the importance of the message are key to success. A teacher advises them to create a favourable atmosphere, speak in an affirmative tone, slow down the language, and highlight the main points. When answering questions, a student should focus on the main points of the topic and not deviate from them.

As a type of problem-based learning, some authors suggest using case methods, regarding them as a participatory and discussion-based way of learning, which provide students with the ability to gain skills in critical thinking, communication, as well as group and teacher interaction. The characteristics of the case method were stated by Bruner (2002). Some major values of the case method are effectiveness (active learning employment, students' self-discovery involvement; teachers serving as facilitators), capacity for critical thinking (questioning skills usage), developing students' framework for making decisions, mimicking the reality, etc.

Case methods are mostly used for teaching professional disciplines when considering events and phenomena in the history of international relations, 
evaluating and forecasting the foreign policy of the countries of the world, as well as analysing international conflicts and ways of their settlement. Such activities help teachers illustrate an idea or raise issues for discussion. For example, mimicking the real events, students analyse the situation and apply their acquired skills in practice. They are also urged to answer the question: "Why has the situation developed in such a way, and how could it have been improved?" This approach helps teachers develop students' critical thinking and promote their self-regulation development.

Thus, students can be encouraged to become more strategic thinkers (i.e., forward thinkers who are not afraid of taking risks while studying, are creative, interested in finding out more effective methods in their ever-changing learning environment, as well as willing to adapt and work effectively instead of just being busy and engaged, etc.) in the online environment by helping them focus on the ways of information processing. These might be such ways as selfquestioning, reflective journal writing, and discussing their thought processes with other learners. Moreover, teachers should also develop effective ways to help students master self-learning, cope with isolation (i.e. lack of interaction), effectively use self-regulatory strategies, and, consequently, develop students' skills of critical thinking while studying online.

Therefore, if these recommendations are considered, first of all, teachers may reach their objectives, improve the level of student knowledge acquisition, and enhance the quality of foreign languages online teaching. Secondly, classes will be verified, and students will equally develop and improve all kinds of skills, i.e., speaking, listening, reading, writing, as well as grammar and general and specific vocabulary. Finally, teachers may boost students' social interaction, teach them to use self-learning, self-regulation techniques, and strategic thinking.

\section{STUDENTS' SELF-REGULATORY ONLINE LEARNING PREREQUISITES}

Self-regulated learning is increasingly important in online education settings, but currently, the existent questionnaires do not cover all the major peculiarities of self-regulated learning in the online context. Consequently, based on the availability in the scientific literature developments, we seek to model the application of questions which learners in the online environment can be prompted to ask themselves during three distinct phases of metacognition planning, monitoring, and evaluating. Moreover, valid measurement and adequate support of self-regulated online learning are of vital importance.

First of all, we consider that planning part should include the range of appropriate strategies and provision of resources effective for achieving goals such as making predictions before reading for comprehension or solving set problems. Second of all, monitoring should consist of the self-testing skills essential to the online learning regulation - the critical analysis of the efficiency 
of the implemented strategies or plans. Third of all, evaluating may refer to the examination of the ongoing progress towards goals which can prompt further planning, monitoring, and evaluating (Mahdavi, 2014). These questions can be incorporated into lesson plans opportunities for the International Relations Department students to practice using them during learning and performance in the online environment.

To develop such students' self-regulatory learning skills, we find it useful to take into account different questionnaires on the issue by Tanner (2012), Jansen et al. (2017), Ertmer and Newby (1996), Nilson (2013), Schraw and Dennison (1994), Anderton (2006) and others. Tanner (2012) developed the set of self-questions that students may ask while planning, monitoring, and evaluating their single class session learning, homework, an exam, or even a whole course. The self-regulated online learning questionnaire developed by Jansen et al. (2017) may be considered of great importance. It is based on existing SRL questionnaires and provides indications for support of self-regulated learning in online education. Ertmer and Newby (1996) present a model of expert learning according to which students' metacognitive awareness of cognitive, motivational, and environmental strategies can be transferred into the regulatory learning control through online reflective thinking. Importantly, the authors discuss the implications that the concept of expert learning has for instructional practices.

As the self-regulated paradigm consists of such categories as knowledge of cognition and regulation of cognition, it is necessary while highlighting major prerequisites of self-regulated online learning to use some questions from a 52-item inventory to measure adults' metacognitive awareness constructed by Schraw and Dennison (1994). Moreover, Anderton (2006), studying the peculiarities to endorse online self-regulated learning tactics of undergraduate teachers, aims at investigating the importance of goal planning, weekly monitoring and evaluation forms within an online class to encourage the use of self-regulated learning approaches. The author highlights that the relationship between student academic achievement and the use of appropriate studying materials to promote self-regulated learning is of great importance and should necessarily be taken into account.

Consequently, we consider that the planning part, which is relevant before learning or performance in the online environment starts, might include the questions dealing with the kind of learning or performance in the online environment; the already existing knowledge about learning or performance in the online environment; the additional or previously gained information needed to do a better job in the online environment; the aims and goals of studying (both of students and teachers); the resources and strategies needed to succeed. Students might also need to master all their strengths and weaknesses, the levels of interest rates, motivation, confidence, efforts etc. Monitoring should consist of the questions relevant during learning or performance in the online environment. These might be the questions about students' awareness of the current activity; their feelings, insights, 
and confusions experienced during learning or performance in the online environment; (ir)relevance of such studying; advantages/disadvantages of the online learning or performance, etc. Evaluation might refer to the questions set up after learning or performance in the online environment, covering students' interests in the levels of accomplishment of their previously set up goals and mastering such online learning or performing. Students might think about the easiest, hardest and most confusing part of the online environment's learning or performance and try to assign their work in the online environment giving themselves appropriate grades.

\section{CONCLUSIONS AND FINAL REMARKS}

In the time of pandemics, the process of studying has faced with significant changes, which were sometimes challenging for both students and the faculty. In order to make online studying valuable for learners and rewarding for teachers, some changes had to be implemented to teaching methods, which would improve the level of student knowledge acquisition and enhance the quality of online teaching of foreign languages and professional disciplines. Some important techniques on how to deal with lack of interaction, master self-learning, promote self-regulation strategies, and become more strategic thinkers during online studying of foreign languages, as well as the possible methods of online teaching of professional disciplines (History of International Relations; Foreign Policy of the Countries of Asia, Africa, and Latin America; International Conflicts; Current Problems of International Relations in the Middle East) were discussed. Therefore, the authors outlined a teacher's explicit instructions, selfassessment tests, personalised feedback to improve students' self-esteem and motivation, self-recordings, self-judgment, and self-evaluation questionnaires as key components of online studying aimed at developing self-learning and self-regulation strategies. In order to increase students' interaction and help shape their critical and strategic thinking, the researchers recommend increasing the amount of time for discussions in small groups; devoting a bit more time to pre-listening and pre-watching discussions; applying a student-ledclass mode; encouraging students to work with primary sources and conduct presentations; and using case study methods. Moreover, some possible challenges were highlighted, and some ways to overcome these difficulties were suggested.

However, the process of studying is bilateral, and the efficiency of students is just as important as the efficiency of teachers. Thus, some major prerequisites of students' self-regulatory online learning were also described.

To sum up, these current results expand an investigation of university learning and performance in the online environment. These suggestions also have important implications for enhancing the online studying process for the International Relations Department students. 


\section{REFERENCES}

[1] Anderton, B. (2006). Using the online course to promote self-regulated learning strategies in pre-service teachers. Journal of Interactive Online Learning, 5(2), 156-177.

[2] Balashov, E., Pasichnyk, I., \& Kalamazh, R. (2016). Intercultural Components of Student Self-realization in International Volunteering. Annual of Social Work, 23(1), 123-139. DOI 316.723: 364.467-057.87.

[3] Bao, W. (2020) COVID-19 and online teaching in higher education: A case study of Peking University. Hum Behav \& Emerg Tech, 2, 113-115. doi:10.1002/hbe2.191.

[4] Boekaerts, M. (1999). Self-regulated learning: Where we are today. International Journal of Educational Research, 31, 445-457.

[5] Brown, J. C., \& Park, H. S. (2016). Longitudinal student research competency: Comparing online and traditional face-to-face learning platforms. Advances in Social Work, 17(1), 44-58. doi:10.18060/20870.

[6] Bruner, R. (2002). Socrates' muse: Reflections on effective case discussion leadership. New York: McGraw-Hill.

[7] Carrier, C. (1984). Do learners make good choices? Instructor Innovator, 29(2), 15-17.

[8] Ertmer, P. A., \& Newby, T. J. (1996). The expert learner: Strategic, self-regulated, and reflective. Instructional Science.

[9] Gilbert, B. (2015). Online learning revealing the benefits and challenges. Education Masters.

[10] Jansen, R. S., Leeuwen, A. V., Janssen, J., Kester, L., \& Kalz, M. (2017). Validation of the self-regulated online learning questionnaire. Journal of Computing in Higher Education, 9, 6-27. doi:10.1007/s12528-016-9125-x.

[11] Mahdavi, M. (2014). An overview: Metacognition in education. International Journal of Multidisciplinary and Current Research, 2, 529-535.

[12] Nguyen, T. (2015). The effectiveness of online learning: beyond no significant difference and future horizons. MERLOT Journal of Online Learning and Teaching, 11(2), 309-319.

[13] Nilson, L. B. (2013). Self-regulated learning \& Questions that self-regulated learners ask themselves. Retrieved from: http://ccwt.wceruw.org/documents/Self-RegLearn-Handout.pdf

[14] Pai, K. (2013). Assessing Online versus face-to-face learning. Proceedings, Global Conference on Business \& Finance, 8(2), 350.

[15] Schraw, G., \& Dennison, R. G. (1994). Assessing metacognitive awareness. Contemporary Educational Psychology, 19, 460-475.

[16] Summers, J., Waigandt, A., \& Whittaker, T. (2005). A comparison of student achievement and satisfaction in an online versus a traditional face-to-face statistics class. Innovative Higher Education, 29(3), 233-250. doi:10.1007/s10755-005-1938-x

[17] Tanner, K. D. (2012). Promoting student metacognition. CBE - Life Sciences Education, 11, 113-120. doi:10.1187/cbe.12-03-0033

[18] Williamson, G. (2015). Self-regulated learning: An overview of metacognition, motivation, and behavior. Journal of Initial Teacher Inquiry, 1, 25-27.

[19] Yang, Y. C. (1993). The effects of self-regulatory skills and type of instructional control on learning from computer-based instruction. International Journal of Instructional Media, 2, 225-241.

[20] You, J. W. \& Kang, M. (2014). The role of academic emotions in the relationship between perceived academic control and self-regulated learning in online learning. Computers $\mathcal{E} E d u$ cation, 77, 125-133. doi:10.1016/j.compedu.2014.04.018

[21] Zimmerman, B. J. (1990). Self-regulated learning and academic achievement: An overview. Educational Psychologist, 25(1), 3-17. 